\title{
3D printing of multiple metallic materials via modified selective laser melting
}

DOI:

10.1016/j.cirp.2018.04.096

\section{Document Version}

Accepted author manuscript

Link to publication record in Manchester Research Explorer

\section{Citation for published version (APA):}

Wei, C., Li, L., Zhang, X., \& Chueh, Y. H. (2018). 3D printing of multiple metallic materials via modified selective laser melting. CIRP Annals, 67(1), 245-248. https://doi.org/10.1016/j.cirp.2018.04.096

\section{Published in:}

CIRP Annals

\section{Citing this paper}

Please note that where the full-text provided on Manchester Research Explorer is the Author Accepted Manuscript or Proof version this may differ from the final Published version. If citing, it is advised that you check and use the publisher's definitive version.

\section{General rights}

Copyright and moral rights for the publications made accessible in the Research Explorer are retained by the authors and/or other copyright owners and it is a condition of accessing publications that users recognise and abide by the legal requirements associated with these rights.

\section{Takedown policy}

If you believe that this document breaches copyright please refer to the University of Manchester's Takedown Procedures [http://man.ac.uk/04Y6Bo] or contact uml.scholarlycommunications@manchester.ac.uk providing relevant details, so we can investigate your claim.

\section{OPEN ACCESS}




\title{
3D Printing of Multiple Metallic Materials via Modified Selective Laser Melting
}

\author{
Chao Wei, Lin Li (1)*, Xiaoji Zhang, Yuan-Hui Chueh \\ Laser Processing Research Centre, School of Mechanical, Aerospace and Civil Engineering, The University of Manchester, Manchester, M13 9PL, UK
}

Selective Laser Melting (SLM) is a powder bed layer-by-layer fusion technique mainly applied for additive manufacturing of 3D metallic components of complex geometry. However, the technology is currently limited to printing a single material across each layer. In many applications such as the manufacture of certain aero engine components, conformably cooled dies, medical implants and functional gradient structures, printing of multiple materials are desirable. This paper reports an investigation into the 3D printing of multiple metallic materials including 316L stainless steel, In718 nickel alloy and Cu10Sn copper alloy within a single build-up process using a specially designed multiple material SLM system combining powder-bed with point by point powder dispensing and selective material removal, for the first time. Material delivery system design, multiple material interactions, and component characteristics are described and the associated mechanisms are discussed.

3D printing, selective laser melting, multiple materials

\section{Introduction}

Selective Laser Melting (SLM) uses a high power laser beam to fully melt powdered material spread on a flat surface, layer-bylayer, to build three dimensional solid models with a high density and well bonded structures based on a CAD file [1-3]. SLM can produce components of variety of materials including metals, ceramics and polymers, while Laser Metal Deposition (LMD), Wire and Arc Additive Manufacturing (WAAM), and Electronic Beam Melting (EBM) are only suitable for printing metallic materials [4]. Existing SLM processes using flat bed powder spreading techniques are only suitable for printing a single material across each layer, thus unsuitable for printing multiple material components, while there may be engineering needs to print multiple materials for specific applications where different material properties are required at different locations, such as aero engine components, medical implants, and dies/moulds.

A critical requirement in multiple material SLM is to deposit at least two discrete powder materials within one layer. A double powder spreading system driven by piezoelectric transducers was applied in a SLM system to fabricate a Fe/Al-12Si dual material structure [5]. Investigators from Singapore demonstrated SLM processed 316L SS/C18400 copper alloy and AlSi10Mg/C18400 copper alloy samples on a commercial SLM system [6,7]. A double ring blade assisted powder spreading system was also applied to sintering parts made of silver/copper [8]. However, none of the deposition methods mentioned above can produce multiple materials over the same layer.

Dissimilar materials must be dispensed locally on the same layer and across different layers at the required location to achieve real 3D material gradient structures and mutiple materials. Lappo et al applied a manual vacuum cleaner to remove powders in required locations and spread the second powder by a roller to fill the same location [9]. Their experiment showed that such an approach caused serious cross-contamination outside the desired second powder deposition region and made multiple material layers shifting. A new 'powder recoating-vacuum cleaningsieving' approach was described for multiple material SLM in which the classic roller mechanism was used to spread the multi- ple materials [10]. Such a system is difficult to be realized in practice due to unavoidable material cross-contamination during repeated powder spreading and vacuum cleaning procedures.

Ultrasonic vibration assisted dry powder dispensing has been investigated widely for different applications [11-15]. The studies demonstrated that dry powder flow rates can be effectively and accurately regulated by controlling the electrical pulses to the piezoelectric transducer. Selective area deposition of different dry powder materials was achievable by employing programmed ultrasonic vibration without sophisticated material pre-mixing preparation. The first demonstration of a multiple nozzle ultrasonic powder deposition method without the use of traditional flat powder bed spreading, for $\mathrm{Cu} / \mathrm{H} 13$ powder selective laser melting was reported by researchers from The University of Manchester in 2008 [16]. The laser printed samples produced were 2D structures.

Until now, there have been no scientific publications showing 3D printing using SLM with multiple materials within a single layer based on dry powder delivery. A suitable discrete multiple powder delivery system for SLM should be a hybrid system combining the traditional powder bed delivery mechanism and a point-by-point powder deposition mechanism. Such a combination is not only required to dispense multiple materials on the same processing layer, but is also needed to generate stable support structures required for complex 3D component printing.

This paper demonstrates a new approach for multiple material SLM by combining powder-bed spreading, point-by-point multiple nozzles ultrasonic dry powder delivery, and point-by-point single layer powder removal to realize multiple material fusion within the same layer and across different layers. In this work, multiple metallic material components 3D printing via SLM was demonstrated. It would also have the potential to print metalceramic-polymer components.

\section{Experimental materials and procedure}

\subsection{Materials}

Gas atomized spherical 316L stainless steel powder (LPW-718AACF, 10-45 $\mu \mathrm{m}$, LPW Technology Ltd., UK), In718 nickel alloy powder (LPW-316-AAHH, 10-45 $\mu \mathrm{m}$ LPW Technology Ltd., UK), 
and Cu10Sn copper-alloy spherical powder of 10-45 $\mu \mathrm{m}$ diameters (Makin Metal Powders Ltd. UK) were used in this investigation. The substrate plates used were ground finished 304 steel sheets of $120 \mathrm{~mm}$ diameter and $12 \mathrm{~mm}$ in thickness.

\subsection{Experimental system description}

A multiple material SLM system was designed and manufactured in this study (see Fig. 1). An x-y-z galvo scanner (Nutfield, 3XB 3axis) was used to scan the laser beam with an $80 \mu \mathrm{m}$ focused beam spot size generated from a $500 \mathrm{~W}$ Ytterbium single-mode, continuous wave (CW) fibre laser (IPG Photonics, YLR-500-WC) of a $1070 \mathrm{~nm}$ wavelength over the target powder bed. A multiple powder delivery system was comprised of a traditional roller assisted powder bed delivery mechanism spreading the main building powder material (316L in this study), and a point-bypoint micro-vacuum selective material removing system for selective, precision single layer powder removal at specific locations, and several ultrasonic dry powder dispensers depositing In718 and Cu10Sn powders respectively according to the designed pattern. The ultrasonic powder dispensers were mounted on an $x-y$ linear stage along with the micro-vacuum selective powder remover. The process operation was in an inert gas environment filled with nitrogen or argon gas having an oxygen gas level less than $0.3 \%$ monitored with a real-time oxygen sensor. Before filling in the inert gas, the operation chamber was vacuumed down to $40 \mathrm{~Pa}$ with a vacuum pump. A fume exaction system was built into the system to remove fumes generated. Although the system had a built-in pre-heating facility, this was not used in the present investigation. A schematic diagram of the experimental set up is shown in Figure 1.

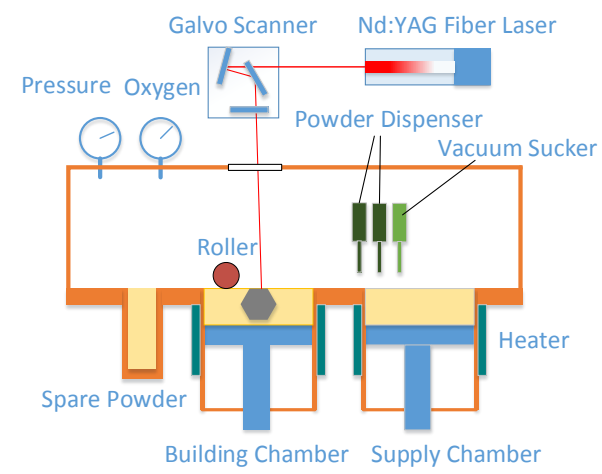

Fig. 1. Schematic diagram of the multiple material SLM system.

\subsection{Multiple material component printing process and procedure}

Fig. 2a describes the multiple material SLM process implemented in this investigation. Firstly, the main powder material, i.e. 316L was spread for one layer of $50 \mu \mathrm{m}$ thickness over the substrate with a motorized roller and powder leveling blades. Then the laser beam melted the desired areas. A selective powder removal process then took place to remove powders of a single layer thickness in defined areas, using the micro-vacuum system. The second/third material powders (In718/Cu10Sn) were then dispensed into the vacuum sucked areas using the ultrasonic powder dispensers and then melted by the laser beam and bonded with the already melted material. Finally, the building platform moved down a distance equal to the layer thickness. All above six steps were repeated until the whole 3D model was fabricated.

Fig. $2 \mathrm{~b}$ shows a selective single layer material removal pattern using the micro-vacuum system.. Fig. 2c demonstrates an example of multiple material deposition combining powder bed spreading $(\mathrm{SiC})$, selective powder removal and selective powder deposition (316L) before laser fusion. There were some margins close to the edges as indicated by the red arrows, due to the width of the expanding zone of the vacuum sucking nozzle being larger than the tool path offset value [17]. Such a problem was solved by vacuum sucking tool path optimization in the following experiments.

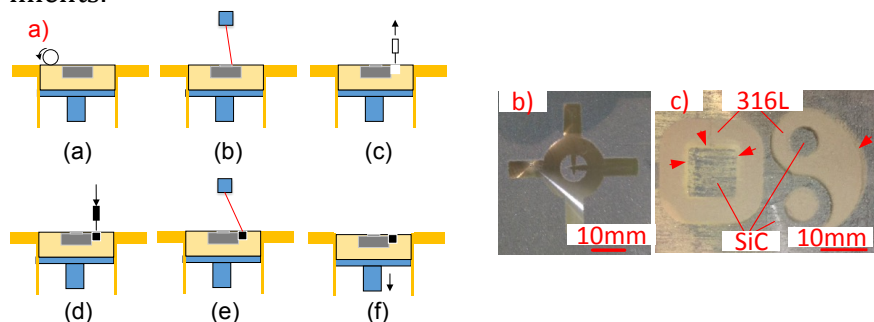

Fig. 2. a) The process flow chart of multiple materials SLM, b) A vacuum cleaned pattern, c) a 316L box and half Yingyang pattern produced by selective powder deposition on a SiC powder layer before laser fusing

Since there have been no software tools for multiple material SLM, a new data preparation procedure and tool was developed. As illustrated in Fig.3, a multiple-material component was considered as an assembly, comprised of a set of single material parts. All these parts were designed with special features on the material interface to enhance the bond. They were then assembled into a single component. At the SLM process data preparation stage, the individual material geometry was converted into an STL format. A global support structure was then created after all the STL files for each material were assembled. Subsequently, slicing and hatching took place for each material separately and the results were exported into the laser control system. The tool paths and CNC G-codes for the selective powder vacuum removal and ultrasonic powder delivery were prepared by a proprietary CNC CAM software tool.

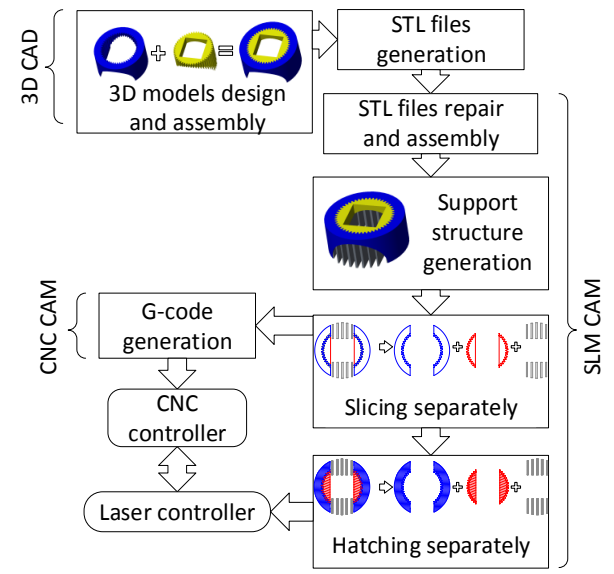

Fig. 3. Illustration of the data preparing procedure for multiple material SLM.

The laser process parameters for fusing three materials used in this investigation are presented in Table 1 . These were derived from preliminary experiments to achieve optimum melting quality and processing efficiency.

Table1: Optimum laser process parameters for multiple material SLM

\begin{tabular}{llll}
\hline Material & $316 \mathrm{~L}$ & $\operatorname{In718}$ & Cu10Sn \\
\hline Laser power $(\mathrm{W})$ & 170 & 180 & 125 \\
Scan speed $(\mathrm{mm} / \mathrm{s})$ & 800 & 857 & 150 \\
Hatch distance $(\mu \mathrm{m})$ & 45 & 45 & 140 \\
Relative hatch angle $\left({ }^{\circ}\right)$ & 90 & 90 & 90 \\
Layer thickness $(\mu \mathrm{m})$ & 50 & 50 & 50 \\
\hline
\end{tabular}

\subsection{Material characterization}

Cross-sections of the SLM parts were prepared by cutting, mounting, grinding with $400^{\#}, 800^{\#}, 1000^{\#}$, and $1200^{\#}$ grid emery 
papers, and finally polished using $1.0 \mu \mathrm{m}$ diamond polishing paste. The polished samples were electro-etched in 10 vol.\% oxalic acid solution. Optical microscopic images of material interfaces were acquired using a Leica DM2700-M microscope. A Durascan80 hardness tester was used to measure the Vickers microhardness on the samples with a $0.3 \mathrm{kgf}$ applied load on the Cu10Sn part and a $0.5 \mathrm{kgf}$ on the $316 \mathrm{~L} / \mathrm{In} 718$ part. The interfaces between $316 \mathrm{~L} / \mathrm{In} 718$ and $316 \mathrm{~L} / \mathrm{Cu} 10 \mathrm{Sn}$ were examined using a scanning electron microscope (SEM, Zeiss Sigma VP FEG SEM) equipped with energy dispersive spectroscopy (EDS, Oxford Instruments X-max ${ }^{N} 150$ ) for elemental mapping.

\section{Result and discussion}

Multiple layer samples of $20 \mathrm{~mm} \times 20 \mathrm{~mm}$ having a $4 \mathrm{~mm}$ width "finger cross" joint zone were printed to investigate multiple material interfaces as shown in Fig. $4 \mathrm{a}$ for $316 \mathrm{~L} / \mathrm{In} 718$ and 316L/Cu10Sn dual material samples (Fig. 4b and c).
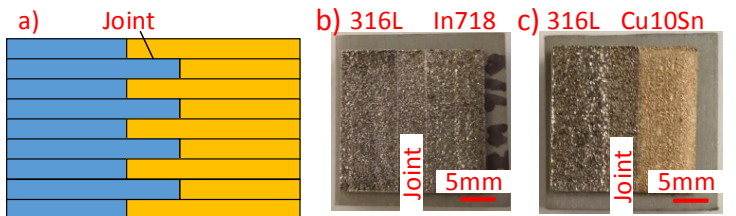

Fig. 4. Experimental samples to study the multiple material interfaces. a) schematic of the "figure-cross" dual material interfaces, b) and c) are the

top view of the processed $20 \times 20 \mathrm{~mm} \mathrm{316L/In718} \mathrm{and} \mathrm{316L/Cu10Sn}$ samples respectively

The optical microscopic images of the cross-sectional view of the multiple material interfaces are shown in Fig. 5 where some pores were found in the ultrasonic deposited powder area as shown in Fig. 5a. The ultrasonic deposited powder surface was uneven due to the ridges between each dispensing tracks. Hence the packing density in such an area was relatively lower, leading to higher porosity. Fig. 5b presents a good bond between 304 SS substrate, 316L SS layer and the Cu10Sn layer. Some part of $\mathrm{Cu}$, migrated into the previously molten 316L layer (see positions pointed by arrows in Fig. 5b). As the liquid phase contact angle of $\mathrm{Cu}$ to the molten $\mathrm{Fe}$ was quite small, it was helpful to increase the thermodynamic driving force for the infiltration[18].

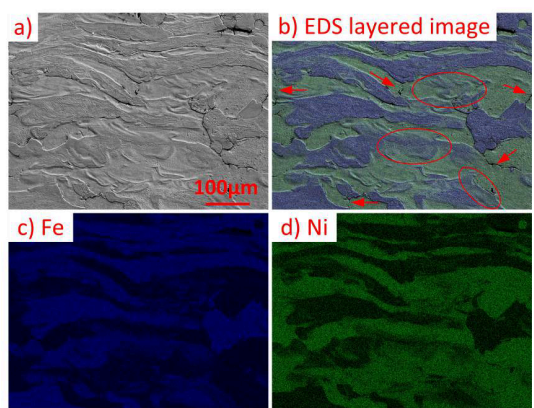

Fig. 6a presents an SEM image of the region described in Fig. 5a, in which some cracks were observed. The EDS mapping results (
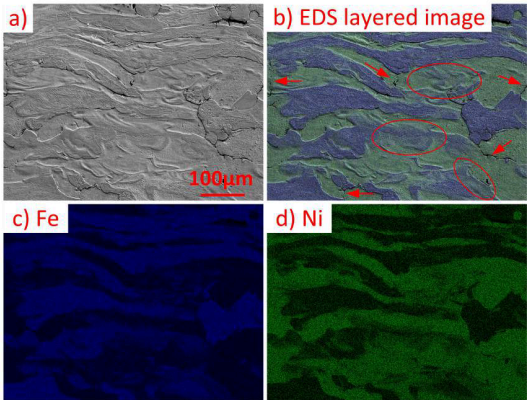

Fig. 6b to d) showed that most of such defects were distributed in the In718 alloy powder region as indicated by the red arrows, deposited by the ultrasonic nozzle. In the roller assisted powder spread process, the packing density of the powder bed was enhanced by the roller compressing, thus cracks/porosity were minimised[19]. However, as the powder particles from the ultrasonic feeding nozzle was not in a compact condition due to lack of an external pressure, cracks and porosity appeared during material phase changes in the laser fusing process. Some 316L/In718 intermixed regions were also found as shown in the elliptic regions in
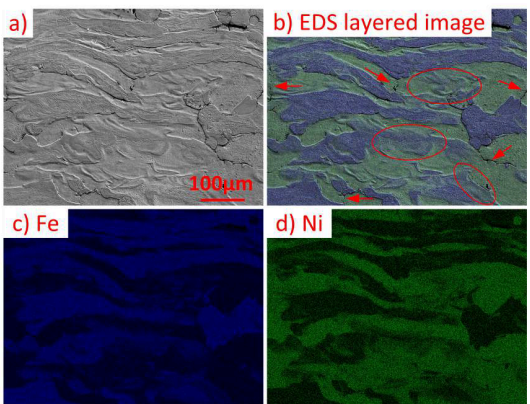

Fig. 6b. In previous studies, investigators usually applied premixed powders for the graded zones, while our study demonstrated that materials could be mixed in the desired regions to achieve required transition properties. SEM evaluation of the 316L/Cu10Sn specimen (Fig. 7a), revealed sound metallurgical bonding at the interface of $316 \mathrm{~L} / \mathrm{Cu} 10 \mathrm{Sn}$ and the interface between 316L and the 304 substrate. No apparent defects were present in the fused 316L region with layers added through the powder-spread roller. On the other hand, some porosity and cracks were observed in the ultrasonic dispensed Cu10Sn powder region indicated by the arrows. It may be caused by the same reason described above. Besides, some isolated light zones, as marked by a rectangle in Fig. 7a, were present in the 316 powder area. Further EDS inspection (Fig. 7f) showed the chemical composition of such zones as $\mathrm{Cu}$, indicating that $\mathrm{Cu}$ element diffused into the Fe area. A dual powder mixing zone was found in the top right of the scanned area by comparing Fig. 7c and $\mathrm{f}$. This could be due to insufficient $316 \mathrm{~L}$ powder vacuum removal. Some residuals of $316 \mathrm{~L}$ powder were blended with the deposited Cu10Sn powder and fused by the subsequent laser fusing process.
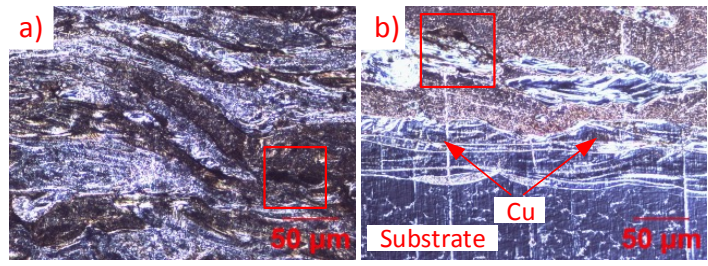

Fig. 5. Optical microscopic images of multiple material interfaces a) 316L/In718 interfaces far from the substrate, b) 316L/Cu10Sn interface close to the substrate. 


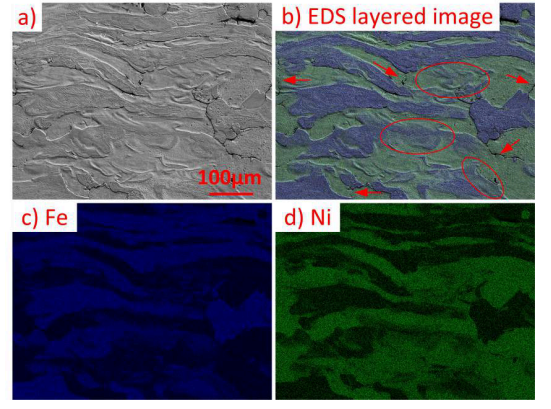

Fig. 6. An SEM image and EDS mappings of 316L-In718 interfaces. a) An SEM image of 316L-In718 interfaces, b) A EDS mapping of the 316-In718 interfaces. c) and d) the Fe and Ni mapping of the 316L-In718 interfaces.

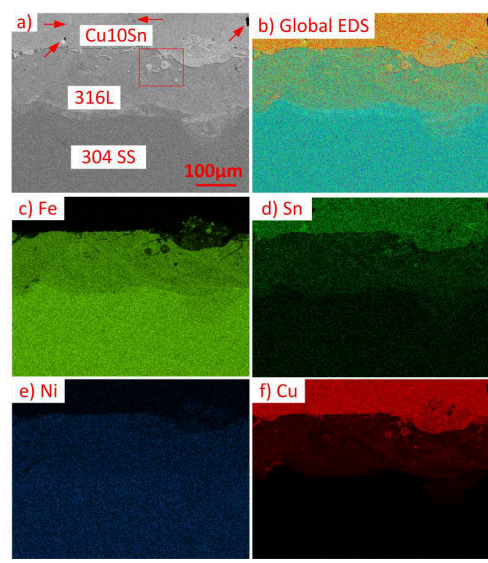

Fig. 7. An SEM image and EDS mappings of 316L-Cu10Sn interfaces. a) the SEM image of 316L-Cu10Sn interfaces, b) An EDS mapping of the 316LCu10Sn interfaces. c) and f) the $\mathrm{Fe}, \mathrm{Sn}, \mathrm{Ni}$ and $\mathrm{Cu}$ mapping of the 316LCu10Sn interfaces.

The Vickers hardness values along the horizontal direction of the SLM samples made of dual materials are shown in Fig. 8. It can be seen that the hardness values of 316L part ranged from $237 \pm 6 \mathrm{HV}$ to $251 \pm 4 \mathrm{HV}$ and those of In718 part ranged from $301 \pm 4 \mathrm{HV}$ to $310 \pm 6 \mathrm{HV}$ with the transition zone having hardness values between those of the two materials. The hardness values of $316 \mathrm{~L}$ and Cu10Sn on the $316 \mathrm{~L} / \mathrm{Cu} 10 \mathrm{Sn}$ sample were $227 \pm 7 \mathrm{HV}$ to $247 \pm 8 \mathrm{HV}$ and $149 \pm 8 \mathrm{HV}$ to $160 \pm 6 \mathrm{HV}$ respectively while the hardness values in the transition zone ranged between those of the two materials. Due to the special "finger cross" joint structure design, material elemental diffusion and bonding were achieved. It is notable that the values of microhardness standard deviation were much higher in the transition zones comparing with those in the single material region as shown in both curves, as the material composition varied in the transition zones..

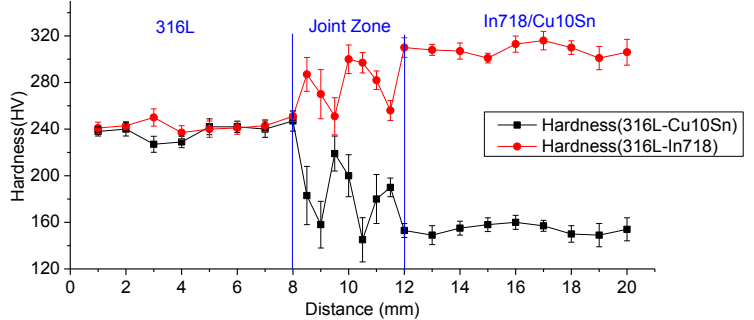

Fig. 8. Vickers hardness values along the horizontal direction of the SLM 316L/In718 sample and the SLM 316L/Cu10Sn sample

A set of 3D complex shapes were manufactured using the proprietary system to demonstrate 3D multiple material printing using the SLM. As shown in Fig. 9 a, the doorstep and the chimney of a simple house were made of Cu10Sn and In718 respec- tively, while the rest of the house was made of 316L material. In Fig. $9 \mathrm{~b}$ and c, golden and silver colors represent the Cu10Sn and 316L material separately. It is notable that the snake headwear of the Sphinx (Fig. 9 b) was made of 316L/Cu10Sn material matrix using the local powder mixing strategy, while the face was made of Cu10Sn and the rest was made of 316L stainless steel. The thin wall structures and dot diameter as shown in Fig. 9 c were 150 $\mu \mathrm{m}$ in thickness and $1 \mathrm{~mm}$ in diameter respectively.
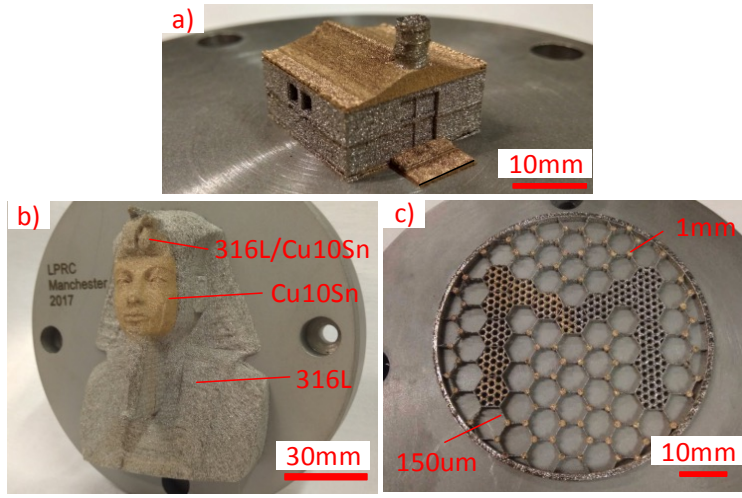

Fig. 9. a) a mini house comprised three materials, b) A multiple color, multi-material statue of Sphinx, c) a dual color grid pattern.

This multiple material 3D printing method may have promising applications for the prouduction of functionally graded components where the matetrial properties can be taylored at different locations. Industrial sectors that may need such a technology would include aerospace (e.g. jet engine components), nuclear (e.g. compopnents that require both high thermal resistance and corrosion resistance), customized jewellery (e.g. combining several types of precious metals), and the medical implants (e.g. artificial teeth with metal core and ceramic shell). Theoretically speaking, all geometry, capable of being produced by traditional single material SLM, should be able to be produced by this multiple material SLM process. The challenges are the support structure design for complex geometry components and material recycling.

\section{Conclusion}

This paper demonstrated a multiple material SLM technology by combining conventional powder-bed spreading with point-bypoint multiple material selective powder removal and point-bypoint dry powder delivery, for the first time. A proprietary experimental SLM equipment and special CAD data preparation procedure for SLM were developed and employed to produce 316L/In718 and 316L/Cu10Sn samples successfully. The feasibility to deposit multiple materials on the same building layer and across different layers was confirmed by the experiment results. A clear distinct sandwich layer distribution and a good metallurgical bonding were obtained at the material interfaces for the material combinations studied. The result also indicated that the special material interface design was helpful to enhance material elemental diffusion, which lead to better bonding. On the other hand, some defects including porosity and cracks were found in the ultrasonically deposited powder region due to un-compressed powders. Future work will include the improvement of the ultrasonic powder dispensing quality and incorporation of ceramics and polymer materials in 3D printing using the special SLM system.

\section{Acknowledgement}

The authors were grateful for The University of Manchester Ph.D. scholarships awarded to Mr. Chao Wei and Mr. Yuan-Hui Chueh. 


\section{References}

[1] Van Hooreweder, B., Kruth, J.-P., 2017, Advanced fatigue analysis of metal lattice structures produced by Selective Laser Melting, CIRP Annals Manufacturing Technology, 66/1:221-224.

[2] Yap, C. -Y., Chua, C.-K., Dong, Z.-L., Liu, Z.-H., Zhang, D.-Q., et al., 2015, Review of selective laser melting: Materials and applications, Applied Physics Reviews, 2/4.

[3] Laumer, T., Wudy, K., Drexler, M., Amend, P., Roth, S., et al., 2014, Fundamental investigation of laser beam melting of polymers for additive manufacture, Journal of Laser Applications, 26/4:42003.

[4] David W Rosen, Brent Stucker, I. G., 2010, Additive manufacturing technologies. Boston, MA: Springer.

[5] Demir, A. G., Previtali, B., 2017, Multi-material selective laser melting of Fe/Al-12Si components, Manufacturing Letters, 11:8-11.

[6] Sing, S.-L., Lam, L. P., Zhang, D.-Q., Liu, Z. H., Chua, C.-K., 2015, Materials Characterization Interfacial characterization of SLM parts in multimaterial processing : Intermetallic phase formation between AlSi10Mg and C18400 copper alloy, Materials Characterization, 107:220-227.

[7] Liu, Z.-H., Zhang, D.-Q., Sing, S.-L., Chua, C.-K., Loh, L.-E., 2014 ScienceDirect Interfacial characterization of SLM parts in multi-material processing : Metallurgical diffusion between 316L stainless steel and C18400 copper alloy, Materials Characterization, 94:116-125.

[8] Regenfuss, P., Streek, a., Hartwig, L., Klötzer, S., Brabant, T., et al., 2007, Principles of laser micro sintering, Rapid Prototyping Journal, 13/4:204212.

[9] Lappo, K., Jackson, B., Wood, D., 2003, Discrete multiple material selective laser sintering (M2SLS): experimental study of part processing, Solid
Freeform Fabrication Symposium, The University of Texas, Austin, TX, 6:109-119.

[10] Chivel, Y., 2016, New approach to multi-material processing in selective laser melting, Physics Procedia, 83:891-898.

[11] Li, X., Choi, H., Yang, Y., 2002, Micro rapid prototyping system for micro components, Thin Solid Films, 420-421:515-523.

[12] Yang, Y., Li, X., 2003, Experimental and analytical study of ultrasonic micro powder feeding, Journal of Physics D: Applied Physics, 36:1349 1354.

[13] Yang, S, Evans, J. R.-G., 2007, Metering and dispensing of powder ; the quest for new solid freeforming techniques, 178:56-72.

[14] Evans, J. R., Yang, S., 2009, Solid Freeforming and Combinatorial Research, Tsinghua Science and Technology, 14/S1:94-99.

[15] Lu, X., Yang, S., Evans, J. R.-G., 2009, Microfeeding with different ultrasonic nozzle designs, Ultrasonics, 49/6-7:514-521.

[16] Al-Jamal, O. M., Hinduja, S., Li, L., 2008, Characteristics of the bond in CuH13 tool steel parts fabricated using SLM, CIRP Annals - Manufacturing Technology, 57/1:239-242.

[17] Zhang, Y., Yang, C., Baker, C., Chen, M., Zou, X., et al., 2014, Effects of expanding zone parameters of vacuum dust suction mouth on flow simulation results, Journal of Central South University, 21/6:2547-2552.

[18] Uzunsoy, D., Chang, I. T.-H., Bowen, P., 2003, Fracture behaviour of selective laser sintered Rapidsteel 2.0 under static and dynamic loading, Mater. Sci. Technol., 19/July:897-901.

[19] Chen, H., Wei, Q., Wen, S., Li, Z., Shi, Y., 2017, Flow behavior of powder particles in layering process of selective laser melting: Numerical modeling and experimental verification based on discrete element method, International Journal of Machine Tools and Manufacture, 123/August:146-159. 